\title{
EL DERECHO YA NO ES LO QUE ERA
}

\author{
Matías Sampedro \\ Universitat de Barcelona \\ sampedromatias@gmail.com
}

Reseña de: Estévez Araújo, J. A. (ed.) (2021). El derecho ya no es lo que era. Las transformaciones jurídicas en la globalización neoliberal, Madrid: Trotta. 573 págs.

Una vez más, el grupo de investigación Isocratía de la Universidad de Barcelona propone un volumen colectivo en el que ha invitado a participar a colegas especialistas de otros ámbitos (temáticos y geográficos). En este caso, recogiendo la fuerza premonitoria de las anteriores entregas, El derecho ya no es lo que era viene a situarse entre las lecturas ineludibles para poder comprender y afrontar las circunstancias críticas en que nos hallamos inmersos. Aunque producto de un trabajo de largo aliento que no contemplaba la emergencia de la pandemia covid-19, muchas encrucijadas actuales son previsibles desde las perspectivas que se nos presentan en este texto, cuyo título debe entenderse en clave de advertencia que esclarece, exento de nostalgia.

Una intención similar se apuntaba en La democracia en bancarrota (2015), dándosenos a entender que, una vez aparentemente superados los momentos más críticos de la crisis posterior al crack del año 2008, eran las instituciones democráticas y la participación popular las que se habían visto fragilizadas (y no aquellos poderes económicos que habían sido parte activa del descalabro financiero, muy fortalecidos en la conducción de los acontecimientos subsiguientes, por el contrario). Se abordaba allí, a través de distintas perspectivas temáticas, la contradicción entre la percepción supuestamente generalizada de formar parte de una comunidad gobernada democráticamente y el "sentimiento antipolítico que caracteriza a la sociedad "democrática» actual" (p. 172). En parte esto explica la pasividad, la docilidad, la aquiescencia ciudadana que acompaña a la ilusión de vivir en las sociedades democráticas existentes como un rasgo psicológico que viene a agregarse al individualismo posesivo en que se funda la doctrina neoliberal. De allí que, para rescatar "la política como la intimidad inextricablemente compartida con otros" (p. $170)$, se hace necesario perseverar en la crítica a la cultura política centrada en el agente individual que busca en solitario la satisfacción y el éxito. 
Ya anteriormente, en El libro de los deberes (2013), se había partido de una concepción distinta a la del individualismo metodológico y la gramática de los derechos centrada en la forma del contrato, que considera a los seres humanos solo en su faceta egoísta y dirigidos a la obtención del máximo beneficio personal. Se trata más bien de una postura epistémica con sentido práctico, que asume la responsabilidad científica hacia su objeto de estudio y busca ponderar con genuina sensibilidad democrática las opciones que los agentes sociales elaboran diariamente con su esfuerzo; por eso Juan Ramón Capella advertía allí que "el proceso de desarticulación de las organizaciones sociales que hemos vivido durante estas últimas décadas mina las bases del aprendizaje del actuar solidario" (p. 12). Se recogía entonces una reivindicación histórica consistente en que la lucha por los derechos es contra las formas de dominación, se da en el campo político y no en una esfera ideal de debate que anule los intereses particulares.

Al hacer hincapié en la existencia de deberes como único contenido posible de los derechos, también, se nos advertía de la debilidad e insuficiencia de una estrategia que esperara el efectivo cumplimiento de éstos por parte del estado, en un contexto en que esta institución se hallaba jaqueada como nunca por un soberano supraestatal difuso que no ha hecho más que acrecentar su incidencia en las últimas décadas.

En el desarrollo de este texto se prefiguraba ya parte del contenido que compone el libro que hoy nos toca comentar. Se prestaba atención a las prácticas de los agentes involucrados en la creación y aplicación del derecho, especialmente aquellos incurriendo en innovaciones con capacidad de modificar el esquema general, como el caso de las corporaciones transnacionales. Así, se constata un desplazamiento importante en el período neoliberal que afecta el contenido de deberes correspondiente a los derechos que se habían ido desplegando para atenuar la dominación en las sociedades industriales capitalistas, por dos vías: la desregulación pública y la privatización de la creación de derecho. Los actores privados pasan a imponer sus criterios de eficacia y legitimidad al conjunto de las poblaciones afectadas por estas nuevas formas de regulación, el poder público detentado por la institución política del estado se vuelve asimétrico y se debilita. La privatización en la creación del derecho se da otorgando a las empresas (eminentemente las transnacionales) capacidad de legislar (previa desregulación estatal) mediante la elaboración de códigos de conducta empresarial o de responsabilidad social corporativa, cuyo objetivo es no obstaculizar el avance de la cultura del management. El resultado es la procedimentalización de los derechos, el vaciado de su contenido sustantivo mediante la implementación de procedimientos de negociación entre partes que, aunque basados preferentemente en la forma contractual, muchas veces no son susceptibles de ser judicializados $y$, en el mejor supuesto, reconocen la apelación a instancias de arbitraje con exiguas garantías. 
Este fenómeno se percibe claramente en el caso del derecho de los trabajadores sometidos por la casa matriz de las corporaciones transnacionales a una competición fraticida entre las subsidiarias de los distintos países donde operan. Pero no es ajeno a otros ámbitos más elusivos para el registro cotidiano, como el de la normativa de protección medioambiental, el derecho a la vivienda (como ha quedado crudamente expuesto con la ola de desahucios que sucedió al estallido de la burbuja hipotecaria fomentada por la desregulación de mercados específicos y la relajación de los instrumentos de control), los derechos a la sanidad, la educación u otros servicios esenciales. Lo que en El libro de los deberes se exponía como "una mancha de aceite" (p. 253) en expansión, caso por caso, se nos presentará ahora con detalle en un corpus más integral y con una definición aguda de sus contornos aún amenazantes.

\section{EL DERECHO YA NO ES LO QUE ERA}

Este libro expone un trabajo sucesivo, de largo recorrido, realizado en parte en una serie de seminarios bajo el mismo título en los que intervinieron varios de los autores y que precedieron a la elaboración de los textos. Así debe comprenderse su carácter orgánico, en el que la división de la tarea analítica incorpora el saber específico de los expertos en cada materia a la mesa común en que se evalúan en toda su dimensión. La separación del volumen en dos partes -general y especial, emulando la arquitectura legal tradicional- responde a esta dinámica de trabajo. Los dos artículos que abren la lectura, cuyo autor coordinó el seminario y se encargó de la presente edición, fungen de base para el resto de intervenciones, proveen un marco general que no encorseta las siguientes contribuciones sino que más bien les ofrece un punto de partida, una exposición exhaustiva de las derivas económica y jurídica que acompañaron las últimas décadas de globalización neoliberal expandida. En la senda de la sociología y la filosofía del derecho, los siguientes capítulos de esta Parte General examinan los aspectos eminentemente políticos en el intento de legitimar jurídicamente un ejercicio de poder oligárquico, en la obstaculización de una pedagogía que permita hacer frente al deterioro ambiental cada vez más exacerbado, en la afectación de distintos ámbitos del derecho por la proliferación incesante de variados procesos de digitalización de la vida social. En la Parte Especial, luego, se nos ofrece una serie de diagnósticos detallados que enriquecen la visión de cada campo particular del derecho.

La fase caótica en que ha ingresado el ordenamiento neoliberal puede apreciarse en el estado actual del Derecho Internacional Económico. Sin el protagonismo excluyente de la paradigmática Organización Mundial del Comercio (sobre todo desde que en 2019 su Órgano de Apelación quedara prácticamente inoperante), en las últimas dos décadas y de manera creciente se han sucedido una serie de tratados bilaterales y acuerdos macro regionales para canalizar el comercio y las inversiones internacionales. En éstos nuevos marcos se introducen -a veces bordeando lo 
testimonial- referencias al resguardo de los derechos laborales, la protección del medioambiente o los derechos humanos, pero también se va más allá de la materia arancelaria y se pone atención en el comercio de servicios y los derechos de propiedad intelectual. No es que la dinámica de integración transnacional de las operaciones económicas se haya interrumpido con la proliferación de estos instrumentos reguladores, muy al contrario, "son también usados como una herramienta estratégica de los estados y otros actores económicos que encontraron limitaciones en seguir modelando las reglas internacionales a través del sistema multilateral del comercio" (p. 438). A las superposiciones e incoherencias normativas resultantes de esta situación, además, habría que añadir la existencia de iniciativas que no contemplan los instrumentos de regulación habituales: el programa a gran escala Nueva Ruta de la Seda, mediante el cual China busca financiar inversiones e infraestructuras en un área a la que proyecta expandir su influencia, o las negociaciones laberínticas que llevan adelante Reino Unido y la Unión Europea como consecuencia del Brexit.

Por incomprensible que pueda parecer este panorama, no deja de ser el resultado de un diseño institucional que corresponde a un estilo de gobernanza característico de la ideología neoliberal. La dimensión económica es primordial en las relaciones internacionales y esto se refleja también en la esfera del Derecho Internacional Público. Si la crisis del año 2008 se mostraba como una oportunidad para acudir a los principios de especialidad normativa y funcional a través de los órganos competentes de Naciones Unidas, finalmente se decidió un esquema de "multilateralismo elitista" (p. 263) como el G20, en el que los estados con mayor protagonismo en el entramado económico y financiero global gestionan medidas coyunturales que no componen un marco regulatorio integrado ni prevén condiciones de interpretación que permitan hacer efectivas las salvaguardas al medioambiente o en derechos humanos. Estas alianzas se imponen "frente a la legitimidad de la acción institucional de organizaciones internacionales con vocación universal en que participan la gran mayoría de estados" (p. 265), desestimando la que debería ser una natural convergencia y cohesión entre áreas regulatorias que se generan a partir de un vínculo sustancial, como las del comercio internacional y del trabajo de manera evidente. Sus mandatos, aunque adolezcan de fundamento normativo, no dejan de ser imperativos: la reforma laboral española de 2012 es un "buen ejemplo de la persuasión legislativa ejercida por el G20" (p. 263) en la reunión de Los Cabos de ese mismo año.

Sobre esta última cuestión, encontramos una descripción pormenorizada del proceso desregulador en el capítulo dedicado al Derecho Laboral. Se expone allí cómo a un breve período inicial con vocación tuitiva, siguió otro de un "estado de reforma permanente" (p. 491), con aval del Tribunal Constitucional. Estas reformas componen un ciclo de reducción de las garantías de estabilidad laboral: la 
desarticulación del modelo (en las reformas de 1984, 1994 y 1997), una reforma de transición (2010) y la construcción de un modelo alternativo de derecho neoliberal del trabajo, en la reforma de 2012. Los resultados inmediatos de la última fueron la desestructuración de la negociación colectiva, la flexibilización en la fijación del salario y la adaptabilidad en las formas y condiciones en que el trabajador lleva a cabo su tarea. En este marco, la aparición y desarrollo de las plataformas digitales, con su régimen de promoción del trabajo autónomo, ha visibilizado la normativa neoliberal en la materia como "la expresión más significativa y acabada de la política legislativa orientada a la hiperflexibilización y desregulación de las relaciones laborales" (p. 494).

Por otra parte, los efectos disruptivos que siguen a la proliferación de la economía de plataformas se constatan también en el ámbito del Derecho Tributario. La capacidad de deslocalización de las compañías digitales, que "pueden ponerse fuera del alcance de la soberanía fiscal de los países donde operan" (p. 481) y, al igual que las corporaciones transnacionales, desplazar la fuente de sus rendimientos imponibles a guaridas fiscales, no hace más que desfinanciar las arcas públicas y empujar a los estados a acrecentar su deuda para paliar una recaudación menguante. Mientras se ensayan proyectos para gravar la generación de valor en el territorio donde efectivamente se realiza y a las operaciones con florecientes y a la vez opacas criptomonedas, la estructura de recaudación fiscal en España ha venido sufriendo un desbalance regresivo desde 2008: los asalariados aportan en gran proporción mediante los impuestos a la renta y al consumo, y aunque se haya reducido la carga impositiva a las sociedades, las grandes empresas y los grandes patrimonios son responsables de tres cuartas partes del fraude estimado.

Si seguimos con los enfoques especialistas, teniendo en cuenta, tal como venimos observando, los desafíos y demandas que acechan a la organización estatal, encontramos asimismo, como no podía ser de otro modo y casi con pertinencia natural, que el Derecho Constitucional pasa por momentos de reflexiones significativas. Más allá de los constreñimientos generales que la asociación en la Unión Europea impone y el valor convencional de su tratadística para los estados miembros, incluso sin la adopción común de una constitución strictu sensu (como se detalla en un capítulo aparte), las garantías constitucionales no han dejado de verse alteradas en las décadas recientes. Como se expone en el texto respectivo, no se trata de que el capital global empuje a un régimen "posestatal, puesto que los estados siguen siendo herramientas extremadamente útiles para los procesos de acumulación de riqueza, sino del devenir posconstitucional de unos estados incapaces ya de dotarse de mecanismos efectivos para la limitación del poder, de los poderes" (p. 337).

En ocasión de la reforma express del artículo 135 de la Constitución Española se ha podido apreciar, por la subordinación resultante, la "fragilidad constitutiva" (p. 
349) de los derechos laborales y sociales allí recogidos. Igualmente, la jurisprudencia del Tribunal Constitucional ha ido confirmando el carácter precario y transitorio de los derechos que componían el estado social pactado en la Constitución de 1978, mediante su desmontaje o severa limitación. De allí que nuestro autor se proponga recuperar para el Derecho Constitucional su función primaria de regulación del poder, para lo cual no es suficiente un constitucionalismo del estado social que no ha podido evitar su desnaturalización y sigue siendo dependiente de "unas condiciones de posibilidad ya caducas" (p. 355). Se nos ofrece "una reflexión constitucional que no quiere desligarse de su núcleo, el poder constituyente, y reivindica por tanto la capacidad de transformar, de ir permanentemente más allá de lo constituido" (p. 336). De pretensiones módicas en la escala inicial, pero coherente en la perseverancia de la acción instituyente, se explora en un "constitucionalismo de lo común", conjunto de "constituyencias" que se opone a los mitos de la modernidad política desde un proceso colectivo. Los comunes son, pues, un recurso obligado ante el avance de poderes con una capacidad invasiva tal que no reconoce la demarcación público/privado. Si bien su concepción puede estar sujeta a controversias, o más bien abierta a debate (no puede ser definitiva: no han sido instituidos aún), proveen un novedoso potencial heurístico en tanto no refieren simplemente a bienes materiales de disponibilidad básica sino también a una dimensión relacional, no están exclusivamente orientados a la actividad productiva sino que incluyen toda una gama de labores reproductivas entre las cuales las de elementales cuidados adquieren visibilidad desde esta perspectiva (y convergentemente, desde la feminista por descontado, dado que han sido y son las mujeres quienes mayormente se han encargado de ellas).

La encomiable apertura que proporciona esta intensificación constituyente al centrarse en lo común debe, no obstante, seguir indagando en las vías de su aplicabilidad. Ante la opción binaria de mercantilización o vaciamiento de los lazos comunitarios que caracteriza a la dinámica globalizadora, hallamos aquí una respuesta equivalente en su intención protectora: "se trata de formas de politizar las necesidades a través del reconocimiento de procesos sociales colectivos en el marco de, pero no subordinado a, la institucionalidad estatal. [Una propuesta] capaz de ofrecer líneas útiles para repensar el modo en que se configura la relación entre sujetos, necesidades y poder" (p. 361). Pero sin un ajuste preciso a algún marco jurídico estatal, como han hecho notar los administrativistas, la concreción efectiva de los comunes sería problemática. Desde el Derecho Administrativo podría considerarse "necesario avanzar hacia la inclusión de cosas que tienen relación con las administraciones públicas, pero que no pertenecen a estas como derechos reales" (p. 517). Frecuentemente, esta vinculación se da al nivel de las administraciones locales, y así el Derecho Administrativo ha tenido que vérselas con situaciones análogas a la provisión del bien común, como en el caso de la "remunicipalización" 
de servicios públicos tan básicos como el suministro de agua. Sin embargo, la tendencia neoliberal también ha sustraído valiosos instrumentos de regulación al Derecho Administrativo, delegándose a veces sus funciones a organizaciones privadas de perfil técnico (como la competencia de regulación sobre la actividad bancaria a cargo del Comité de Basilea) aunque sin legitimidad democrática de ningún tipo, otras veces como resultado de su propia dinámica privatizadora por la cual el estado pasó de ser prestador de servicios a oficiar de garante.

Tomando en cuenta esta metamorfosis en la función del estado podemos observar, en el encuadre general del Derecho Privado, que se trata en realidad de un regreso a su lugar destinado en el marco del "derecho igual" del orden burgués liberal, eso sí, en condiciones muy distintas, al punto de que es posible hablar ahora de un "estado negociador" en el entorno de un "derecho inconexo" (p. 302), en el que las formas jurídicas clásicas se han desligado de los arquetipos a que hacían referencia. Así encontramos que el despliegue de la forma contrato, concebida para la regulación de los intercambios entre sujetos jurídicamente iguales, se ha hipertrofiado en una magnitud que hasta su propio objetivo se ha visto desviado. Las innovaciones desarrolladas para posibilitar la circulación de riqueza sin necesidad de un intercambio sustantivo se aprecian en el caso de los contratos derivados (swaps, futures, options), originalmente concebidos como protección ante eventuales fluctuaciones en tipos de interés o cotizaciones de divisas, entre otras. Llevados al terreno especulativo de las Ilanas apuestas y ajenos ya a la suerte de los supuestos bienes subyacentes, "en 2018 se invirtieron en estos "productos financieros» 2200 billones de euros, o sea, una riqueza equivalente a 33 veces el PBI mundial" (p. 293). Este fenómeno es posible, sin dudas, gracias a una impresionante expansión tecnológica que redunda en la "despolitización del derecho, el cual habría reemplazado el telos de un proyecto social compartido por la técnica" (p. 280).

Por lo tanto, se nos presenta un mundo sin confines, como resultado de "ensanchamientos semánticos de técnicas jurídicas del derecho liberal" aplicadas a "potencialidades antes impensables" (p. 301). Aunque, en verdad, estos nuevos horizontes no puedan ser de provecho irrestricto, algo evidente al contemplar el uso de las patentes como "forma de apropiación de los recursos a título originario" (p. 290), que tampoco se basan en un intercambio sino en un hecho solo accesible a partir de un determinado nivel de poder. Nos encontramos finalmente, como se expone minuciosamente en un capítulo dedicado, con una notable expansión del instituto de la propiedad por múltiples vías: se alargan los plazos para los derechos de copyright, se otorgan permisos de materia patentable que incluyen entidades tan estrafalarias como bacterias manipuladas, fragmentos de ADN, procedimientos matemáticos empaquetados en software, virus. Todo parece ser susceptible de explotación mercantil. 
Ahora bien, si las modificaciones que se han dado durante el período de globalización neoliberal en los subcampos jurídicos antes mencionados parecen facilitar la actividad económica privada a través de las fronteras y en los propios mercados nacionales, existen indicios de que el mismo orden proyectado contempla la marginación de sectores de la sociedad como contracara de la concentración de riqueza y poder que se viene verificando, y se dispone a gestionar la contestación eventual. Las transformaciones aceleradas en el Derecho Penal durante las últimas décadas son orientativas en este sentido. La sanción de la Ley de Seguridad Ciudadana española de 2015 no es más que el corolario estridente en la implantación de un punitivismo que se ciñe a la atribución individual y desestima la responsabilidad de la sociedad en el delito, con lo que se da la circunstancia de que entre los más desprotegidos y socialmente relegados es donde el "derecho penal del enemigo" puede llegar a encontrar a los delincuentes más "peligrosos". Por cierto, una persecución tan efectista del delito no hubiera sido posible sin la concurrencia espectacularizante de los medios de comunicación masivos, expertos en la modulación de la sensación de inseguridad y alarma. El Derecho Penal afronta, en consecuencia, serios problemas de legitimación democrática cuando se compone como un "instrumento de comunicación social propicio para la reafirmación simbólica de valores tales como el orden y la seguridad frente a la inquietud y el temor que se dejan sentir en las sociedades de nuestros días" (p. 322).

Más aún, ¿cómo no reconocer una sociedad del hipercontrol cuando, en otro plano, son los ciudadanos quienes colaboran con su propia vigilancia a partir del suministro permanente de información personal a agentes públicos y privados desde sus teléfonos móviles? La sugerente hipótesis de un ciudadano confesor moldeado por dispositivos de gubernamentalidad foucaultianos ocupa un artículo con profusión de datos ad hoc en la Parte General. Y en consonancia, un colofón inquietante en la consolidación del nuevo paradigma actuarial en Derecho Penal puede venir dado por la aplicación de programas informáticos predictivos para evaluar (e incluso decidir) la concesión de los distintos grados de ejecución de penas. Esta y otras incursiones de la Inteligencia Artificial en el mundo del derecho son analizadas en un capítulo que nos alerta acerca de los peligros que implica la introducción de mecanismos radicalmente nuevos en procedimientos jurídicamente vinculantes, entre otros la posibilidad de un sesgo discriminatorio inherente al diseño de herramientas cibernéticas capaces de evolucionar desde la automatización a la autonomización en sus operaciones.

Nos encontramos, por lo tanto, con una dificultad inédita para la vigencia del derecho como institución democrática, que no puede ser resuelta desde el mero formalismo sin recabar en los resortes políticos y pedagógicos de la vida social. ¿Cómo se podría, si no, poner coto jurídico a unas elites dirigentes que no han dudado en propiciar la fractura de los marcos estatales cuando ello les permitía acaparar más 
riquezas? Vemos que con un sector público exánime, la economía doméstica fue arrastrada a una vorágine crediticia que le permitiera hacer frente por vía de la contratación privada a todo tipo de provisiones, desde la vivienda al cuidado de la salud pasando por las pensiones, los servicios esenciales, la educación o una miríada de productos superfluos de promoción incesante. Se impone el contraste entre una sofisticación material y tecnológica inconmensurable y la realidad miserable de gran parte de la humanidad a la que se le niega la posibilidad mínima de ejercer un trabajo y se la empuja a veces a un periplo migratorio que violenta su dignidad. Por añadidura, la globalización más acuciante es aquella no querida de la crisis ecológica que, lejos de poder administrarse con los instrumentos que gestionan la economía industrial o financiera, al abordarse con un mínimo de sensatez analítica nos depara la imposibilidad de colapsos selectivos y nos obliga a ejercitar un aprendizaje innovador que contemple la hipótesis del colapso como ejercicio "que estimula la capacidad de anticipación" (p. 168), que pueda imaginar mundos posibles más allá de la certificada declinación irreversible de los recursos energéticos y un belicismo imperante que no da muestras fiables de autocontención.

Una empresa de tal calibre requiere, previamente, un trabajo de desmontaje analítico del denso tejido económico y jurídico que ha hecho posible este estado de cosas. El profesor Estévez Araújo se ha tomado esa tarea y nos expone los rasgos definitorios de la globalización neoliberal con una minuciosa selección de fuentes. Las lábiles etiquetas de autorregulación o gobernanza adquieren sentido específico cuando se desbroza la complejidad de un sistema económico en el que el protagonismo de unas empresas transnacionales de tamaño inusitado, articuladas en cadenas globales de valor, se entremezcla con la desregulación, informatización y cientifización que ha experimentado el mundo de las finanzas, lo que ha dado lugar a que se hable de una financiarización de la economía (p. 30). La estrategia que se ha seguido para que esta proeza sea posible ha sido la simultánea desestatalización del derecho y privatización de la regulación. La protección eminentemente estatal que el derecho de propiedad ofrecía se ha mostrado insuficiente en estas circunstancias, ha sido necesario disponer garantías adicionales que cubran la actuación de los agentes económicos en un mercado global, reconociendo la propiedad intelectual en autoría, marcas y patentes, blindando el estatus de los inversores internacionales.

La suposición de una nueva lex mercatoria, luego, pretende darle entidad jurídica a lo que no es más que la libertad autoconcedida con que las partes contratantes se dotan para establecer los regímenes normativos aplicables a sus componendas y los órganos susceptibles de arbitrar si se producen desacuerdos. La defección de los estados en sus atributos soberanos que permite que algunas de sus instituciones sean instrumentalizadas de este modo, entonces, obedece a la presión que ejercen unos agentes tan poderosos que se permiten promover el desmantelamiento del estado intervencionista y acotar la participación ciudadana, pero no pueden prescindir de un 
mínimo aval discursivo que proporcione al menos la apariencia de racionalidad o legitimidad a sus actuaciones.

Se nos ofrece en este libro, al fin de cuentas, una ventana a los desafíos de distinta naturaleza que enfrenta el derecho: la relativa intangibilidad de los bienes a tutelar, su rol en las técnicas de gobierno, la equivocidad de los actores constreñidos, situaciones no previstas en los ordenamientos, la instrumentalización de sus especialidades con sentido desnaturalizante, la proliferación terminológica ambigua o confusa y la desarticulación jurisdiccional entre otros. El resultado, lejos de la didáctica de la complacencia o la dogmática que legitima lo existente, estremece, tal el mundo que nos rodea, clama injusticias, prácticas dañinas y ocultamientos deliberados. Un diagnóstico así lúcido y realista nos provee una base indispensable a la hora de elaborar propuestas que restituyan sentido democrático a la acción política. Podemos ver, como sugiere Capella, el estado de los derechos a la luz de los hechos. De este modo es posible, por ejemplo, identificar los obstáculos que se le presentarán a los migrantes para acceder a un estatus ciudadano cada vez más retaceado a amplias franjas de la población, pero también la reciente red normativa que se les tenderá desde la esfera laboral o penal, por mencionar las más evidentes. Es posible, en otro orden, exigir que las empresas transnacionales cumplan al menos sus evanescentes compromisos públicos, como punto de partida en la búsqueda de una regulación sensata, y evaluar las distintas posibilidades de financiación de los proyectos que promuevan los intereses comunitarios según el alcance de sus consecuencias totales. $\mathrm{Y}$, mientras tanto, ir pensando y construyendo alternativas viables, reparadoras, solidarias.

Del derecho y del revés, el futuro ya llegó, y tampoco es lo que era. Queda en nuestras manos este manual de instrucciones para usuarios comprometidos en dar respuesta a las necesidades urgentes y las demandas colectivas que los derechos deberían expresar, un compendio del desquicio jurídico y social globalizado por el credo neoliberal, y sucinto catálogo de las herramientas políticas y normativas todavía disponibles para intentar otro camino, invitación siempre perpleja al aprendizaje en común. 